Quim. Nova, Vol. 36, No. 1, 190-194, 2013

\title{
SÍNTESE E HIDRÓLISE DE AZALACTONAS DE ERLENMEYER-PLÖCHL MEDIADAS POR RADIAÇÃO MICRO-ONDAS EM APARELHOS DOMÉSTICO E DEDICADO: EXPERIMENTOS DE QUÍMICA ORGÂNICA PARA A GRADUAÇÃO
}

\author{
Silvio Cunha*, Raimundo Francisco dos Santos Filho e Valéria Belli Riatto \\ Instituto de Química, Universidade Federal da Bahia, Campus de Ondina, 40170-290 Salvador - BA / Instituto Nacional de Ciência \\ e Tecnologia em Energia e Ambiente, Universidade Federal da Bahia, Campus de Ondina, 40170-290 Salvador - BA, Brasil \\ Glauber Antonio Albuquerque Dourado \\ Universidade Federal do Recôncavo da Bahia, 45300-000 Amargosa - BA, Brasil
}

Recebido em 18/6/12; aceito em 27/8/12; publicado na web em 7/12/12

\begin{abstract}
SYNTHESIS AND HYDROLYSIS OF ERLENMEYER-PLÖCHL AZALACTONES MEDIATED BY MICROWAVE RADIATION IN DOMESTIC AND DEDICATED OVENS: UNDERGRADUATE ORGANIC CHEMISTRY EXPERIMENTS. This work describes a green chemistry experiment for the synthesis of Erlenmeyer-Plöchl azalactones mediated by microwave irradiation, employing both dedicated and domestic equipment. Hippuric acid was reacted with equimolar amounts of benzaldehyde, $p$-chloro-benzaldehyde or $p$ - $N, N$-dimethyl-benzaldehyde in acetic anhydride as the solvent. Acid hydrolysis of obtained 4-benzylidene-2-phenyloxazol-5(4H)one under microwave and convectional heating afforded Z- -(benzoylamino)cinnamic acid at a 51-61.5\% yield. The UV-Vis molecular spectra of 4-benzylidene-2-phenyloxazol-5(4H)-one and 4-(4'- $N, N$-dimethylbenzylidene)-2-phenyloxazol-5(4H)-one were obtained in ethanol, $\mathrm{CH}_{2} \mathrm{Cl}_{2}$ and DMSO and bathochromic shift was observed for the latter azalactone.
\end{abstract}

Keywords: hypuric acid; undergraduate organic chemistry experiment; green chemistry.

\section{INTRODUÇÃO}

O ensino experimental da Química passa por um período de revitalização no Brasil, devido à atualização da infraestrutura das Instituições Federais de Ensino Superior (IFES), como já destacado em artigo recente. ${ }^{1}$ Adicionalmente, a modernização da infraestrutura de pesquisa, intrinsecamente associada à pós-graduação e principalmente vinculada aos Institutos Nacionais de Ciência e Tecnologia (INCTs), aos Programas de Grupos de Excelência (PRONEXs) e ao contínuo apoio do Programa Pró-Equipamentos da CAPES e dos Programas de Infraestrutura das FAPs, impactam diretamente na qualidade dos cursos de graduação, uma vez que equipamentos modernos passam a estar disponíveis em diversos laboratórios de pesquisa, proporcionando seu emprego também em atividades de ensino experimental na graduação. Por exemplo, a aquisição de reatores de micro-ondas dedicados para laboratório, em quantidade significativa, ${ }^{2,3}$ tem permitido o desenvolvimento de experimentos didáticos para a graduação e de química orgânica em particular. ${ }^{4}$

Em adição aos aspectos supracitados, o ensino experimental da Química Verde (QV) tem assumido proporção cada vez maior e relatos de experimentos destinados à graduação são crescentes no Brasil. ${ }^{5}$ Dessa forma, reações promovidas ou aceleradas por irradiação de micro-ondas, empregando abordagens de reações one-pot, dominó e/ou multicomponente são aspectos que devem ser inseridos na formação moderna dos futuros profissionais da química.

Em função do nosso interesse continuado na formulação de propostas de aulas experimentais para o ensino de química orgânica, ${ }^{6}$ descrevemos aqui a síntese de heterociclo polifuncionalizado e sua reação de hidrólise, empregando tanto o forno de micro-ondas doméstico quanto o reator dedicado para reações químicas, de forma a permitir o emprego do experimento em diversas realidades de infraestrutura de laboratório de graduação. Adicionalmente, o heterociclo selecionado para ser sintetizado foi o núcleo das 4-arilideno-2-feniloxazol-5-onas,

*e-mail: silviodc@ufba.br pois a preparação deste tipo de substância é indicada em livros textos destinados ao ensino experimental de química orgânica, ${ }^{7}$ e pode ser feita a comparação do método empregando-se aquecimento convencional com o método de aquecimento através da irradiação por micro-ondas. Tão importante quanto todos estes aspectos, a aula aqui desenvolvida reforça a importância de se ampliar o ensino de heterociclos como alvo sintético e como intermediário em síntese orgânica nos cursos da graduação.

\section{SÍNTESE DOS HETEROCICLOS 4-ARILIDENO- 2-FENILOXAZOL-5-ONAS: AZALACTONAS DE ERLENMEYER-PLÖCHL}

Azalactonas de Erlenmeyer-Plöchl são 4-arilideno-2-feniloxazol-5-onas, intermediários sintéticos versáteis na síntese de aminoácidos. ${ }^{8}$ Quando a sua preparação é inserida em aulas de graduação a estratégia envolve sempre aquecimento convencional, sendo empregada a $N$-fenilglicina (1, ácido hipúrico) ou a $N$-acetilglicina 4, mas o benzaldeído é sempre o aldeído empregado nesta reação de Perkin em condições de aquecimento convencional, sob refluxo, Esquema 1.7,9

Apesar destes experimentos cumprirem o papel de introduzir a química de heterociclos em aulas experimentais da graduação,

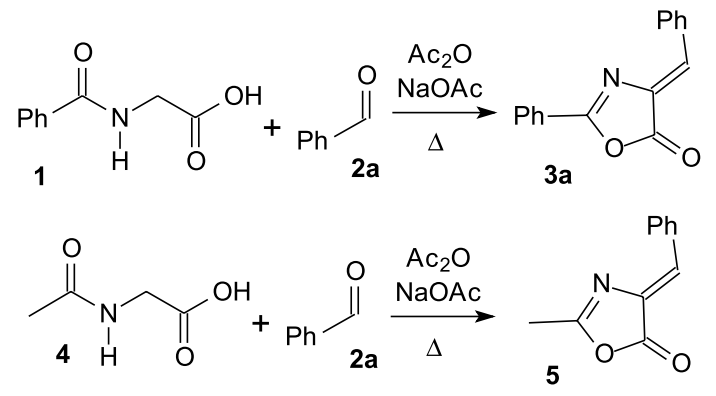

Esquema 1. Síntese das azalactonas de Erlenmeyer-Plöchl descritas nos livros de graduação ${ }^{7,9}$ 
as abordagens descritas ainda refletem a perspectiva sintética do século XIX, pois não incorporam os avanços e preocupações das preparações sintéticas modernas. Por exemplo, os procedimentos destinados a aulas práticas empregam excesso do benzaldeído que varia de 30 a $900 \%{ }^{7,9}$ e mesmo procedimentos recentes descritos em artigos científicos empregam excesso do aldeído. ${ }^{10}$

Existem relatos do uso de micro-ondas na síntese da azalactona derivada do ácido hipúrico e benzaldeído, mas empregam suportes sólidos, além do mencionado excesso do aldeído. ${ }^{11}$ Para o nosso experimento didático, decidimos manter as condições do experimento as mais simples possíveis, para que possa ser utilizado nos mais diversos laboratórios de ensino. Por este motivo, foi necessário reavaliar a reação de síntese das azalactonas de Erlenmeyer-Plöchl para que o procedimento a ser aplicado empregasse a menor quantidade dos reagentes, preferencialmente sem excesso do aldeído ou do ácido hipúrico, e tomou-se o benzaldeído como aldeído de estudo, Esquema 2. A Tabela 1 sumaria os dados deste estudo, inclusive com outros benzaldeídos substituídos. Dessa forma, este experimento emprega tanto o forno de micro-ondas doméstico quanto o dedicado para a síntese das algumas azalactonas de Erlenmeyer-Plöchl, 3a-c, Esquema 2. Apesar de ser possível realizar adaptações no forno doméstico para ser empregado em reações químicas e também calibrá-lo para avaliar a potência nominal a fim de garantir melhor reprodutibilidade, ${ }^{4} \mathrm{o}$ forno doméstico aqui utilizado foi empregado como fornecido pelo fabricante e, se o professor assim desejar, a calibração pode ser inserida como parte integrante da aula, ficando esta decisão condicionada ao tempo disponível do curso experimental.

Diversas variáveis experimentais foram investigadas para a reação modelo entre o ácido hipúrico e o benzaldeído, processada no forno de micro-ondas doméstico (Tabela 1, Entradas 1 a 7). Para a obtenção do produto $3 \mathbf{a}$, tanto o emprego de 4 ou 6 min totais de irradiação, com pulsos de irradiação de $1 \mathrm{~min}$, fornecem praticamente o mesmo rendimento (Entradas 3 e 5, 38 e $41 \%$ de rendimento,
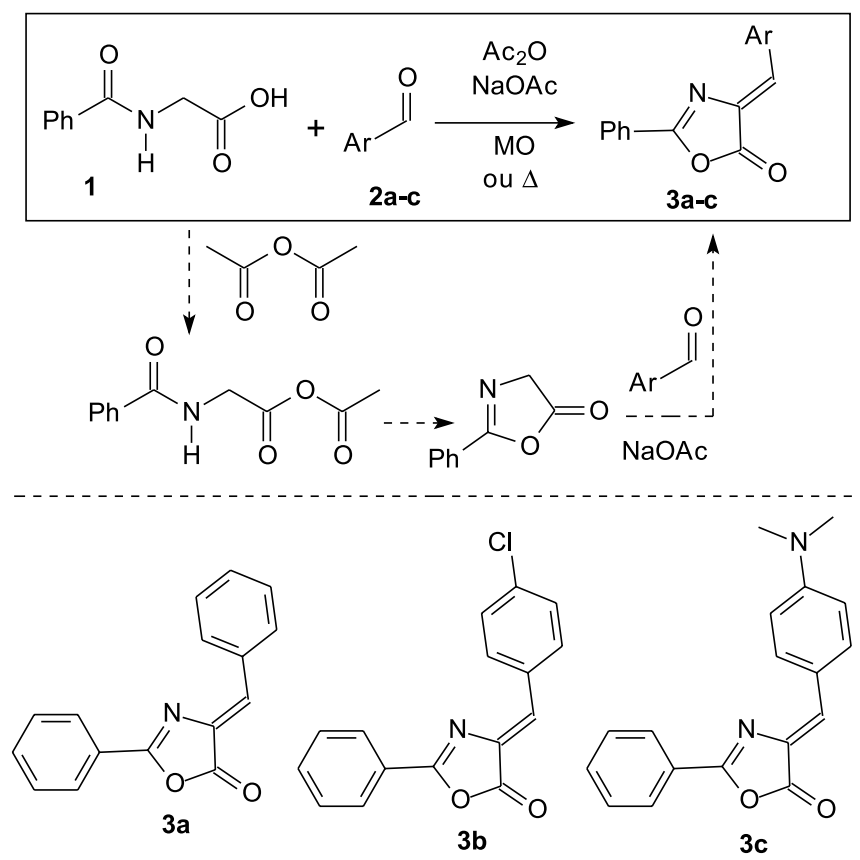

Esquema 2. Síntese das azalactonas de Erlenmeyer-Plöchl

respectivamente). Para o derivado do $p$-cloro-benzaldeído o tempo total de 3 min fornece rendimento comparável ao do benzaldeído (Entrada 9). Há leves variações na cor do sólido obtido 3a em função do tempo total, mas a maior diferença ocorre para o tempo total de 9 min (Entrada 7). Para fins de comparação, a Figura 1S, material suplementar, apresenta fotos dos sólidos obtidos, onde a variação das cores pode ser verificada. O melhor rendimento de $\mathbf{3} \mathbf{a}$ foi obtido quando a reação foi realizada no reator dedicado (Entrada 8), mas consideramos que o rendimento obtido no aparelho doméstico ainda

Tabela 1. Condições das reações, propriedades e rendimentos das azalactonas 3a-c

\begin{tabular}{|c|c|c|c|c|c|c|c|c|}
\hline \multirow{2}{*}{ Entrada } & \multirow{2}{*}{$\mathrm{Ar}$} & \multirow{2}{*}{$\begin{array}{l}\text { Tempo total (min) e } \\
\text { intervalos de tempo }\end{array}$} & \multicolumn{3}{|c|}{ Massa (mg) e mmol empregados } & \multirow{2}{*}{$\begin{array}{l}\text { Tratamento para } \\
\text { precipitação }\end{array}$} & \multirow{2}{*}{$\begin{array}{l}\mathrm{PF}\left({ }^{\circ} \mathrm{C}\right) \mathrm{e} \\
\text { aspecto }\end{array}$} & \multirow{2}{*}{$\begin{array}{l}\text { Rend. }(\%) \\
\text { massa }[\mathrm{mg}]\end{array}$} \\
\hline & & & Ácido & ico Ald & $\mathrm{AcONa}$ & & & \\
\hline 1 & $\mathrm{Ph}$ & $\begin{array}{c}2 \\
(1+1)\end{array}$ & $\begin{array}{l}358,0 \\
(2)\end{array}$ & $\begin{array}{l}246,2 \\
(2)\end{array}$ & $\begin{array}{c}164,3 \\
(2)\end{array}$ & $\begin{array}{c}10 \mathrm{~mL} \\
\text { (etanol) }\end{array}$ & $\begin{array}{l}\left.\text { 162-163,6 (Lit. }{ }^{11} 166\right) \\
\text { amarelo claro }\end{array}$ & $\begin{array}{c}15 \\
{[74]}\end{array}$ \\
\hline 2 & $\mathrm{Ph}$ & $\begin{array}{c}3 \\
(1+1+1)\end{array}$ & $\begin{array}{c}181,6 \\
(1)\end{array}$ & $\begin{array}{c}115,7 \\
(1)\end{array}$ & $\begin{array}{l}87,8 \\
(1)\end{array}$ & $\begin{array}{c}5 \mathrm{~mL} \\
\text { (etanol) }\end{array}$ & $\begin{array}{c}\text { 161,7-164,0 } \\
\text { amarelo claro }\end{array}$ & $\begin{array}{c}26 \\
{[65,7]}\end{array}$ \\
\hline 3 & $\mathrm{Ph}$ & $\begin{array}{c}4 \\
(1+1+1+1)\end{array}$ & $\begin{array}{l}363,5 \\
(2)\end{array}$ & $\begin{array}{l}266,3 \\
(2,5)\end{array}$ & $\begin{array}{c}162,4 \\
(2)\end{array}$ & $\begin{array}{l}10 \mathrm{~mL} \\
\left(\mathrm{H}_{2} \mathrm{O}\right)\end{array}$ & $\begin{array}{c}\text { 163,6-165 } \\
\text { amarelo claro }\end{array}$ & $\begin{array}{c}38 \\
{[194,2]}\end{array}$ \\
\hline 4 & $\mathrm{Ph}$ & $\begin{array}{c}4 \\
(1+1+1+1)\end{array}$ & $\begin{array}{c}360,2 \\
(2)\end{array}$ & $\begin{array}{l}216,2 \\
(2,5)\end{array}$ & $\begin{array}{l}170,1 \\
(2)\end{array}$ & $\begin{array}{c}10 \mathrm{~mL} \\
\text { (etanol) }\end{array}$ & $\begin{array}{c}\text { 162,7-164,5 } \\
\text { amarelo claro }\end{array}$ & $\begin{array}{c}29,5 \\
{[149,4]}\end{array}$ \\
\hline 5 & $\mathrm{Ph}$ & $\begin{array}{c}6 \\
(1+1+1+1+1+1)\end{array}$ & $\begin{array}{l}358,2 \\
(2)\end{array}$ & $\begin{array}{l}252,5 \\
(2,4)\end{array}$ & $\begin{array}{c}164,4 \\
(2)\end{array}$ & $\begin{array}{c}10 \mathrm{~mL} \\
\text { (etanol) }\end{array}$ & $\begin{array}{c}155,7-162,0 \\
\text { amarelo claro }\end{array}$ & $\begin{array}{c}41 \\
{[205,2]}\end{array}$ \\
\hline 6 & $\mathrm{Ph}$ & $\begin{array}{c}6 \\
(2+2+2)\end{array}$ & $\begin{array}{l}361,0 \\
(2)\end{array}$ & $\begin{array}{l}222,1 \\
(2)\end{array}$ & $\begin{array}{l}164,2 \\
(2)\end{array}$ & $\begin{array}{c}10 \mathrm{~mL} \\
\text { (etanol) }\end{array}$ & $\begin{array}{c}162,2-163,8 \\
\text { amarelo claro }\end{array}$ & $\begin{array}{c}29 \\
{[144,6]}\end{array}$ \\
\hline 7 & $\mathrm{Ph}$ & $\begin{array}{c}9 \\
(3+3+3)\end{array}$ & $\begin{array}{c}361,0 \\
(2)\end{array}$ & $\begin{array}{l}329,8 \\
(3)\end{array}$ & $\begin{array}{c}168,3 \\
(2)\end{array}$ & $\begin{array}{c}10 \mathrm{~mL} \\
\text { (etanol) }\end{array}$ & $\begin{array}{c}164-166,2 \\
\text { amarelo esverdeado }\end{array}$ & $\begin{array}{c}28 \\
{[79,6]}\end{array}$ \\
\hline 8 & $\mathrm{Ph}$ & 1 & $\begin{array}{c}304,6 \\
(1,8)\end{array}$ & $\begin{array}{l}180,4 \\
(1,7)\end{array}$ & $\begin{array}{l}139 \\
(1,7)\end{array}$ & $\begin{array}{c}5 \mathrm{~mL} \\
\text { (etanol) }\end{array}$ & $\begin{array}{c}163,3-164,2 \\
\text { amarelo claro }\end{array}$ & $\begin{array}{c}71,5 \\
{[302,7]^{b}}\end{array}$ \\
\hline 9 & 4-Cl-Ph & $\begin{array}{c}3 \\
(1+1+1)\end{array}$ & $\begin{array}{l}181,1 \\
(1)\end{array}$ & $\begin{array}{c}156,7 \\
(1)\end{array}$ & $\begin{array}{l}82,20 \\
(1)\end{array}$ & $\begin{array}{c}10 \mathrm{~mL} \\
\text { (etanol) }\end{array}$ & $\begin{array}{l}\text { 194,9-197,0 (Lit. }{ }^{11} \text { 197) } \\
\text { amarelo claro }\end{array}$ & $\begin{array}{c}38 \\
{[109,8]}\end{array}$ \\
\hline 10 & $4-\mathrm{N}\left(\mathrm{CH}_{3}\right)_{2}$ & $\begin{array}{c}4 \\
(1+1+1+1)\end{array}$ & $\begin{array}{l}364,8 \\
(2)\end{array}$ & $\begin{array}{l}298,4 \\
(2)\end{array}$ & $\begin{array}{l}164,8 \\
(2)\end{array}$ & $\begin{array}{c}10 \mathrm{~mL} \\
\text { (etanol) }\end{array}$ & $\begin{array}{c}213,5-215,6\left(\text { Lit. }^{12} 215\right) \\
\text { vinho }\end{array}$ & $\begin{array}{c}9 \\
{[53,3]}\end{array}$ \\
\hline 11 & $4-\mathrm{N}\left(\mathrm{CH}_{3}\right)_{2}$ & 1 & $\begin{array}{c}364,8 \\
(2)\end{array}$ & $\begin{array}{c}298,4 \\
(2)\end{array}$ & $\begin{array}{c}164,8 \\
(2)\end{array}$ & $\begin{array}{l}10 \mathrm{~mL} \\
\text { (etanol) }\end{array}$ & $\begin{array}{c}\text { 213-215 } \\
\text { vermelho }\end{array}$ & $\begin{array}{c}62 \\
{[185,0]^{b}}\end{array}$ \\
\hline
\end{tabular}

aTodas as reações realizadas no equipamento de micro-ondas doméstico, exceto as reações das entradas 8 e 11 . ${ }^{\text {}}$ Reação realizada no reator de micro-ondas dedicado. 
é adequado para a realização do experimento nas instituições que não possuem o reator dedicado, e a análise da diferença entre os rendimentos, em função da natureza do aparelho, pode ser matéria integrante da análise dos resultados dos alunos.

O procedimento desenvolvido com o forno de micro-ondas doméstico é aplicável também ao $p$-cloro-benzaldeído, apesar do rendimento ter sido modesto, mas ainda adequado para uma aula de graduação. Todavia, quando o $p$ - $N, N$-dimetil-benzaldeído foi empregado, o rendimento da azalactona $\mathbf{3 c}$ foi muito baixo quando comparado com a reação processada no reator dedicado (Entradas 10 e 11) e a variação de cor foi a mais significativa (Figura 1S, material suplementar). Entretanto, os pontos de fusão e os espectros na região do infravermelho dos dois sólidos são comparáveis entre si, e concordantes com os dados disponíveis na literatura (Entradas 10 e 11 da Tabela 1). A cor vinho do sólido obtido $\mathbf{3 c}$ pode estar associada à formação de impureza colorida não identificada, em quantidade traço, uma vez que os dados físicos deste sólido vinho não variam significativamente quando comparado ao sólido vermelho.

\section{A COR E A ESTRUTURA: EXPLORANDO AS PROPRIEDADES ELETRÔNICAS DAS AZALACTONAS DE ERLENMEYER-PLÖCHL}

Em função da grande difereça de cor entre as subtâncias 3a,c o professor pode explorar, além da síntese das preparações das azalactonas mediadas por micro-ondas, os aspectos estruturais responsáveis por alterações na estrutura eletrônica e nas cores dessas substâncias através da análise dos espectros de absorção molecular na região do UV-Visível (UV-Vis).

A variação na estrutura das azalactonas de Erlenmeyer-Plöchl 3a,c aqui sintetizadas resume-se à modificação do substituinte na posição para do anel aromático do aldeído empregado, como indicado no Esquema 2. A mudança de um átomo de hidrogênio para um de cloro praticamente não influencia na cor do sólido obtido, que passa de amarelo pálido em 3a para amarelo em $\mathbf{3 b}$. Todavia, a cor vermelha intensa de $\mathbf{3 c}$, obtido na reação com o reator dedicado (Figura 1S, material suplementar), contrasta com as outras azalactonas e deve estar associada ao forte efeito doador de elétrons do grupo dimetilamino desta azalactona. Para quantificar esta diferença, os estudantes podem obter os espectros UV-Vis dos compostos 3a,c e correlacioná-los com as respectivas estruturas. Esta abordagem integra o que os graduandos aprendem nos cursos de química analítica com os de química orgânica e reforça o aprendizado da técnica UV-Vis para compostos orgânicos.

No espectro de absorção molecular na região do UV-Vis, os valores dos comprimentos de onda referentes ao máximo de absorção para 3c são 467, 473 e 483 nm nos solventes etanol, $\mathrm{CH}_{2} \mathrm{Cl}_{2}$ e DMSO, respectivamente (Figura 1), enquanto que os valores correspondentes para o derivado 3a são 361, 364 e 367 nm (Figura $2 \mathrm{~S}$, material suplementar). Esta variação observada na região de absorção de 3a para 3c, do ultravioleta para o visível, representa um deslocamento batocrômico e o professor pode explorar este fato para correlacionar com a variação na estrutura das duas substâncias. Por exemplo, é possível associar a cor de $\mathbf{3 c}$ com a maior contribuição da estrutura canônica 3c' para o híbrido de ressonância, onde a perda da aromaticidade do anel benzênico é relativamente compensada pela formação da estrutura do anel oxazólico, Esquema 3. ${ }^{12}$ Para o derivado 3a com o hidrogênio no lugar do grupo dimetilamino de $\mathbf{3 c}$, e mesmo para o derivado $\mathbf{3 b}$ com o átomo de cloro, a participação da estrutura de ressonância equivalente deve ser muito pequena em função da inabilidade do hidrogênio e do cloro em estabilizar esta estrutura canônica quando comparado ao efeito doador de elétrons do grupo dimetilamino de $\mathbf{3 c}$.

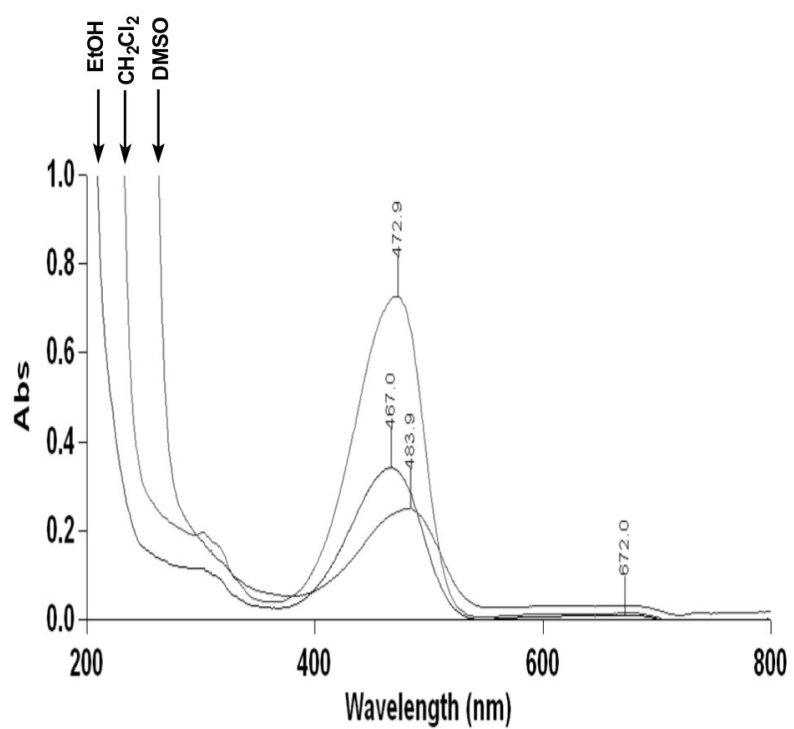

Figura 1. Espectros de absorção molecular para $3 \mathrm{c}$ em $\mathrm{CH}_{2} \mathrm{Cl}_{2}\left(\begin{array}{llll}5 & \times 10^{-7}\end{array}\right.$ mol/L $\mathrm{L}^{-1}$, absorbância máxima 0,738), EtOH $\left(3 \times 10^{-7} \mathrm{~mol} / \mathrm{L}^{-1}\right.$, absorbância máxima 0,342) e em DMSO (5 x $10^{-7} \mathrm{~mol} / \mathrm{L}^{-1}$, absorbância máxima 0,251). Para os espectros com linhas coloridas, ver Figura 3S, material suplementar<smiles>CCCCCCCCCCc1ccc(N(C)C)cc1</smiles>

Esquema 3. Duas estruturas canônicas para a azalactona $3 c$

É possível também invocar qualitativamente a diferença relativa de energia dos orbitais HOMO-LUMO para 3a e 3c. Assim, os alunos podem relacionar que o menor valor de $\Delta \mathrm{E}_{\text {номо-Luмо }}$ se refere a $\mathbf{3 c}$, pois é esta substância que apresenta o maior comprimento de onda para a máxima absorção, como medido em todos os três solventes investigados. Adicionalmente, o efeito solvatocrômico para $\mathbf{3 c}$ pode também ser explorado nesta aula, pois há uma clara distinção nos comprimentos de onda de absorção máxima nos três solventes, com efeito batocrômico do etanol para o DMSO (Figura 1), bem mais significativo que em 3a (Figura 2S, material suplementar). Pode-se, também, explorar a intensidade da associação solvente-soluto calculando as absortividades molares para $\mathbf{3 a}, \mathbf{c}$ em cada um dos solventes, o que permite ao aluno explorar este tema em toda a sua extensão. Resta ainda a possibilidade do professor aprofundar as explicações dos efeitos hipsocrômicos observados nos espectros de absorção molecular de 3c quando são comparados os espectros obtidos na mesma concentração nos solventes $\mathrm{CH}_{2} \mathrm{Cl}_{2}$ e DMSO, e relacionar este efeito com a maior estabilização de $\mathbf{3 c}$ em DMSO em função da maior polaridade deste solvente.

\section{HIDRÓLISE ÁCIDA DA AZALACTONA 3a}

As azalactonas de Erlenmeyer-Plöchl são intermediários para a síntese de aminoácidos. ${ }^{13}$ Para isto, podem ser hidrolisadas e então hidrogenadas, ou a sequência inversa. Todavia, na etapa de hidrolise é sempre empregada condição alcalina, sendo necessária uma etapa final de acidificação. Decidimos avaliar a hidrólise ácida da azalactona 3a empregando aquecimento convencional e por irradiação de 
micro-ondas, usando $\mathrm{H}_{2} \mathrm{SO}_{4}$ como catalisador, Esquema 4. Os dois procedimentos fornecem o ácido Z-2-benzoilamino-3-fenilacrílico 6 em rendimentos adequados para aulas de graduação, onde se pode destacar a simplicidade do procedimento e a facilidade de separação do produto sólido. $\mathrm{O}$ emprego do $\mathrm{H}_{2} \mathrm{SO}_{4}$ como catalisador parece ser essencial, pois, ao contrário dos dados aqui descritos, há relatos de insucesso na hidrólise ácida de $\mathbf{3 a} \cdot{ }^{13} \mathrm{~A}$ análise dos dados de $\mathrm{RMN}$ de ${ }^{1} \mathrm{H}$ revela que a estereoquímica $Z$ da dupla ligação carbono-carbono é preservada na etapa de hidrólise ácida, em concordância com outros ácidos análogos de $\mathbf{6}$ preparados através da rota alcalina. ${ }^{13}$<smiles>CCO[SH](=O)(O)CC1N=C(c2ccccc2)OC1=O</smiles>

3a

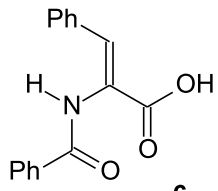

6
Aquecimento convencional: $62,5 \%(90 \mathrm{~min})$ Aquecimento por MO: $51 \%(20 \mathrm{~min})$

Esquema 4. Hidrólise ácida da azalactona $3 a$

A etapa de hidrólise ácida também se coaduna aos princípios da Química Verde, uma vez que promove a redução dos resíduos gerados, pois dispensa o emprego de solução de base forte, seguida de solução ácida para neutralização. Neste ponto, o professor pode fazer uma comparação direta dos dois procedimentos aqui relatados com os existentes nos livros textos, demonstrando a economia atômica e o cálculo do fator E para as duas propostas de hidrólise, alcalina e ácida, onde ficam evidentes as vantagens desta última. ${ }^{13}$ Para a análise aqui proposta, recomendamos a abordagem descrita no livro didático de Correa e Zuin ${ }^{5}$ e o artigo de Merat e Gil, ${ }^{14}$ pois são bem adequados à introdução destas métricas em curso de graduação.

Apesar do menor rendimento da reação realizada no reator de micro-ondas dedicado, o tempo de reação foi significativo menor. Dessa forma, dependendo da duração da aula experimental, é possível realizar a síntese e a hidrólise da azalactona numa mesma aula ou em aulas consecutivas. Os experimentos aqui apresentados foram executados por alunos do curso optativo "Síntese Orgânica Verde", ministrado por nós no IQ da UFBA, e se mostraram adequados tanto para aulas de 2 quanto de $4 \mathrm{~h}$.

\section{CONCLUSÃO}

Foram sintetizadas azalactonas de Erlenmeyer-Plöchl em rendimentos satisfatórios, empregando tanto forno de micro-ondas doméstico quanto aparelho de micro-ondas dedicado a laboratórios, de forma que a aula proposta é passível de aplicação imediata como parte integrante de disciplinas experimentais de química orgânica, uma vez que emprega procedimentos rápidos, simples e de fácil execução. O desenvolvimento dos procedimentos de síntese da azalactona 3a e sua hidrólise ácida, sem o uso de excesso de reagentes e por aquecimento convencional ou irradiação de micro-ondas, representa simplificações adequadas para aulas experimentais, pois minimiza resíduos. Adicionalmente, o estudo das propriedades eletrônicas por meio da obtenção dos espectros na região do UV-Vis proporciona a correlação dessas características espectrais com o efeito dos substituintes das estruturas e dos solventes, o que não é geralmente enfatizado nos cursos experimentais de química orgânica. Não menos importante, a execução do experimento proporciona a discussão da química de heterociclos, de métodos modernos de promover reações químicas empregando micro-ondas e de Química Verde, que são temas importantes para a formação contemporânea de profissionais da Química.

\section{MATERIAL SUPLEMENTAR}

Foto dos sólidos coloridos, espectros de absorção da região do UV-Visível para 3a, espectros na região do infravermelho e espectros de RMN de ${ }^{1} \mathrm{He} \mathrm{e}^{13} \mathrm{C}$ para compostos selecionados encontram-se disponíveis gratuitamente em http://quimicanova.sbq.org.br, na forma de arquivo PDF.

\section{PARTE EXPERIMENTAL}

Os aldeídos sólidos foram empregados nas reações sem tratamento prévio e o benzaldeído foi destilado antes do uso. Os pontos de fusão foram determinados em um aparelho de placa aquecida Microquímica MQAPF 301 e não foram corrigidos. Os espectros na região do infravermelho foram de obtidos na forma de discos de $\mathrm{KBr}$ em um aparelho Shimadzu IR Affinity-1. Os espectros de RMN foram obtidos num aparelho Varian Gemini 300 e os deslocamentos químicos estão descritos em unidades de ppm a partir da referência (TMS). O reator de micro-ondas dedicado empregado foi o modelo Discover da marca CEM e o forno doméstico foi da marca Electrolux, modelo MEF33.

\section{Síntese das azalactonas de Erlenmeyer-Plöchl}

\section{Método 1 - aquecimento em micro-ondas doméstico}

Em um erlenmeyer de $50 \mathrm{~mL}$ preparar uma mistura de $363,5 \mathrm{mg}$ de ácido hipúrico (2 mmol), 266,3 mg de benzaldeído (2,5 mmol), $162,4 \mathrm{mg}$ de acetato de sódio ( $2 \mathrm{mmol}$ ) em $5 \mathrm{~mL}$ de anidrido acético. Colocar um funil com colo curto no erlenmeyer (para evitar projeções durante o aquecimento) e colocar no aparelho de micro-ondas doméstico contendo, no centro da cavidade do forno, um béquer de $200 \mathrm{~mL}$ com $100 \mathrm{~mL}$ de água à temperatura ambiente. Programar o micro-ondas para aquecer na potência máxima por 1 min. Repetir o aquecimento por mais $3 \mathrm{~min}$, trocando a água do béquer entre os intervalos. Ao término deste tempo, esperar o erlemneyer atingir a temperatura ambiente e verter o meio reacional em água gelada contendo gelo picado e filtrar a vácuo o sólido que se forma, recristalizar 3a em etanol e secar ao ar. Para a síntese de $\mathbf{3 b}$ e $\mathbf{3 c}$ ver os dados descritos na Tabela 1 e Figura 1S, material suplementar.

\section{Método 2 - aquecimento por micro-ondas dedicado}

Em um tubo de reação de $10 \mathrm{~mL}$ para reator dedicado de micro-ondas adicionar 418,0 $\mathrm{mg}$ de ácido hipúrico (2,3 mmol), 180,40 mg de benzaldeído (1,7 mmol), 139,45 mg de acetato de sódio (1,7 $\mathrm{mmol}$ ) e $5 \mathrm{~mL}$ de anidrido acético. Introduzir uma barra magnética no tubo, fechar com o septo específico para o tubo do reator e introduzir na cavidade do aparelho de micro-ondas dedicado. Aquecer a mistura reacional com agitação vigorosa a $125^{\circ} \mathrm{C}$ a $300 \mathrm{~Hz}$ por 1 min. O sólido amarelo que se forma adere completamente na parede do tubo. Para remover este sólido, adicionar $5 \mathrm{~mL}$ de álcool etílico e aquecer o tubo em banho-maria até total solubilização. Resfriar em banho de gelo e filtrar a vácuo o sólido amarelo 3a em formato de agulhas, lavar com álcool etílico gelado e secar ao ar, P.F. 163,3-164,2 ${ }^{\circ} \mathrm{C}$. Para a síntese de $\mathbf{3 c}$ ver os dados descritos na Tabela 1 e Figura $1 \mathrm{~S}$, material suplementar.

Hídrólise ácida das azalactona de Erlenmeyer-Plöchl 3a: síntese do ácido Z-2 -benzoilamino-3-fenilacrílico 6

\section{Método 1 - aquecimento convencional}

Em um balão de $50 \mathrm{~mL}$ adicionar de $50 \mathrm{mg}$ de 4-benzilideno-2-feniloxazol-5-ona 3a, $5 \mathrm{~mL}$ de água, $5 \mathrm{~mL}$ de álcool etílico e 2 gotas de ácido sulfúrico concentrado. Introduzir uma barra magnética no 
balão e conectá-lo a um condensador de refluxo. Aquecer a mistura reacional em um banho de óleo sob refluxo com agitação vigorosa durante 90 min (a suspensão torna-se solução durante o aquecimento). Após esse tempo, a mistura reacional é resfriada até a temperatura ambiente e então vertida para um béquer contendo gelo picado e agitada até precipitar um sólido branco. O sólido formado é filtrado a vácuo e seco ao ar, fornecendo 33,5 mg de 6 como sólido branco, $62,5 \%$ de rendimento, PF $224,4-226,5^{\circ} \mathrm{C}$ (Lit. ${ }^{8} 222-224{ }^{\circ} \mathrm{C}$ ).

\section{Método 2 - aquecimento por micro-ondas}

Em um tubo de reação de $30 \mathrm{~mL}$ para reator dedicado de micro-ondas adicionar $50 \mathrm{mg}$ de 4-benzilideno-2-feniloxazol-5-ona $\mathbf{3 a}$, $7 \mathrm{~mL}$ de solução $1: 1$ de água/etanol e 2 gotas de ácido sulfúrico concentrado. Introduzir uma barra magnética no tubo, fechar com o septo específico para o tubo do reator e introduzir na cavidade do aparelho de micro-ondas dedicado. Aquecer a mistura reacional com agitação vigorosa durante 20 min a $130^{\circ} \mathrm{C}$ na potência máxima. Após esse tempo, a mistura reacional é resfriada até a temperatura ambiente e então vertida para um béquer contendo gelo picado e agitada até precipitar um sólido branco. O sólido formado é filtrado a vácuo e seco ao ar, fornecendo $25,4 \mathrm{mg}$ de $\mathbf{6}$ como sólido branco, $51 \%$ de rendimento, PF $230,6-232,2{ }^{\circ} \mathrm{C}$ ( Lit. $^{8} 222-224{ }^{\circ} \mathrm{C}$ ).

\section{AGRADECIMENTOS}

Ao suporte financeiro do Conselho Nacional de Desenvolvimento Científico e Tecnológico - CNPq, Coordenação de Aperfeiçoamento de Pessoal de Nível Superior - CAPES e Fundação de Amparo à Pesquisa do Estado da Bahia - FAPESB. Também agradecemos ao CNPq pela bolsa de doutorado de R. F. Santos Filho e ao CNPq pela bolsa de produtividade em pesquisa de S. Cunha.

\section{REFERÊNCIAS E NOTAS}

1. Lima, E. C. D.; Alcantara, G. B.; Damasceno, F. C.; Moita Neto, J. M.; Galembeck, F.; Quim. Nova 2010, 33, 1991.

2. Nos últimos 5 anos foram adquiridos cerca de 120 reatores de micro-ondas dedicados para laboratório da marca CEM, de acordo com informações prestadas ao autor pelo Sr. E. P. Goncalves da empresa Superlab/ Brasil, por comunicação privada, abril de 2012. Da marca ANTOPAR foram cerca de 16 equipamentos, de acordo com informações prestadas ao autor, por comunicação privada, pelo Sr. A. Ferreira da empresa Polimate, em maio de 2012.
3. Para uma visão geral da pesquisa em síntese orgânica no Brasil empregando micro-ondas, ver: de Souza, R. O. M. A.; Miranda, L. S. M.; Quim. Nova 2011, 34, 497.

4. Rosini, F.; Nascentes, C. C.; Nóbrega, J. A.; Quim. Nova 2004, 27, 1012; Teixeira, E. F.; dos Santos, A. P. B.; Bastos, R. S.; Pinto, A. C.; Kümmerle, A. E.; Coelho, R. R.; Quim. Nova 2010, 33, 1603; Graebin, C. S.; Eifler-Lima, V. L.; Quim. Nova 2005, 28, 73; da Silva, F. C.; Ferreira. V. F.; de Souza, M. C. B. V.; Quim. Nova 2006, 29, 376; Konrath, E. L.; Piedade, M.; Eifler-Lima, V. L.; Quim. Nova 2012, 35, 1887.

5. Corrêa, A. G.; Zuin, V. G.; Química Verde: Fundamentos e Aplicações, EdUFSCar: São Carlos, 2009; Cunha, S.; de Santana, L. L. B.; Quim. Nova 2012, 35, 642; Cunha, S.; Lustosa, D. M.; Conceição, N. D.; Fascio, M.; Magalhães, V.; Quim. Nova 2012, 35, 638.

6. Cunha, S.; Beretta, M.; Fascio, M.; Santos, A. O.; Rodrigues Jr., M. T.; Bastos, R. M.; Quim. Nova 2005, 28, 364; Cunha, S.; Lião, L. M.; Bonfim, R. R.; Bastos, R. M.; Monteiro A. P. M.; Alencar, K. S.; Quim. Nova 2003, 26, 425; Cunha, S.; Quim. Nova 2003, 26, 948.

7. Soares, B. G.; Souza, N. A.; Pires, D. X.; Química Orgânica: Teoria e Técnicas de Preparação, Purificação e Identificação de Compostos Orgânicos, Ed. Guanabara S.A.: Rio de Janeiro, 1988.

8. Shinkai, H.; Toi, K.; Kumashiro, I.; Seto, Y.; Fukuma, M.; Dan, K.; Toyoshima, S.; J. Med. Chem. 1988, 31, 2092; Muneer, M.; Tikare, R.; Kamat, P.; George, M.; Can. J. Chem. 1987, 65, 1624.

9. Furniss, B. S.; Hannaford, A. J.; Smith, P. W. G.; Tactchell, A. R.; Vogel's Textbook of Practical Organic Chemistry, $5^{\text {th }}$ ed., Longman Scientific \& Technical: Singapore, 1989.

10. Chandrasekhar, S.; Karri, P.; Tetrahedron Lett. 2007, 48, 785; Jursic, B. S.; Sagiraju, S.; Ancalade, D. K.; Clark, T.; Stevens, E. D.; Synth. Commun. 2007, 37, 1709. Para a preparação em larga escala, ver: Chavez, F.; Kennedy, N.; Rawalpally, T.; Williamson, R. T.; Cleary, T.; Org. Process Res. Dev. 2010, 14, 579.

11. Conway, P. A.; Devine, K.; Paradisi, F.; Tetrahedron 2009, 65, 2935; Bautista, F. M.; Campelo, J. M.; García, A.; Luna, D.; Marinas, J. M.; Romero, A. A.; J. Chem. Soc., Perkin Trans. 2 2002, 227.

12. Murthy, Y. L. N.; Christopher, V.; Prasad, U. V.; Bisht, P. B.; Ramanaih, D. V.; Kalanoor, B. S.; Ali, S. A.; Synth. Met. 2010, 160, 535.

13. Suh, J.; Lee, E.; Myoung, Y. C.; Kim, M.; Kim. S.; J. Org. Chem. 1985 , 50, 977; Cleary, T.; Brice, J.; Kennedy, N.; Chavez, F.; Tetrahedron Lett. $\mathbf{2 0 1 0}, 51,625$.

14. Merat, L. M. O. C.; Gil, R. A. S.; Quim. Nova 2003, 26, 779. 


\section{SÍNTESE E HIDRÓLISE DE AZALACTONAS DE ERLENMEYER-PLÖCHL MEDIADAS POR RADIAÇÃO MICRO-ONDAS EM APARELHOS DOMÉSTICO E DEDICADO: EXPERIMENTOS DE QUÍMICA ORGÂNICA PARA A GRADUAÇÃO}

\section{Silvio Cunha*, Raimundo Francisco dos Santos Filho e Valéria Belli Riatto}

Instituto de Química, Universidade Federal da Bahia, Campus de Ondina, 40170-290 Salvador - BA / Instituto Nacional de Ciência e Tecnologia em Energia e Ambiente, Universidade Federal da Bahia, Campus de Ondina, 40170-290 Salvador - BA, Brasil

Glauber Antonio Albuquerque Dourado

Universidade Federal do Recôncavo da Bahia, 45300-000 Amargosa - BA, Brasil

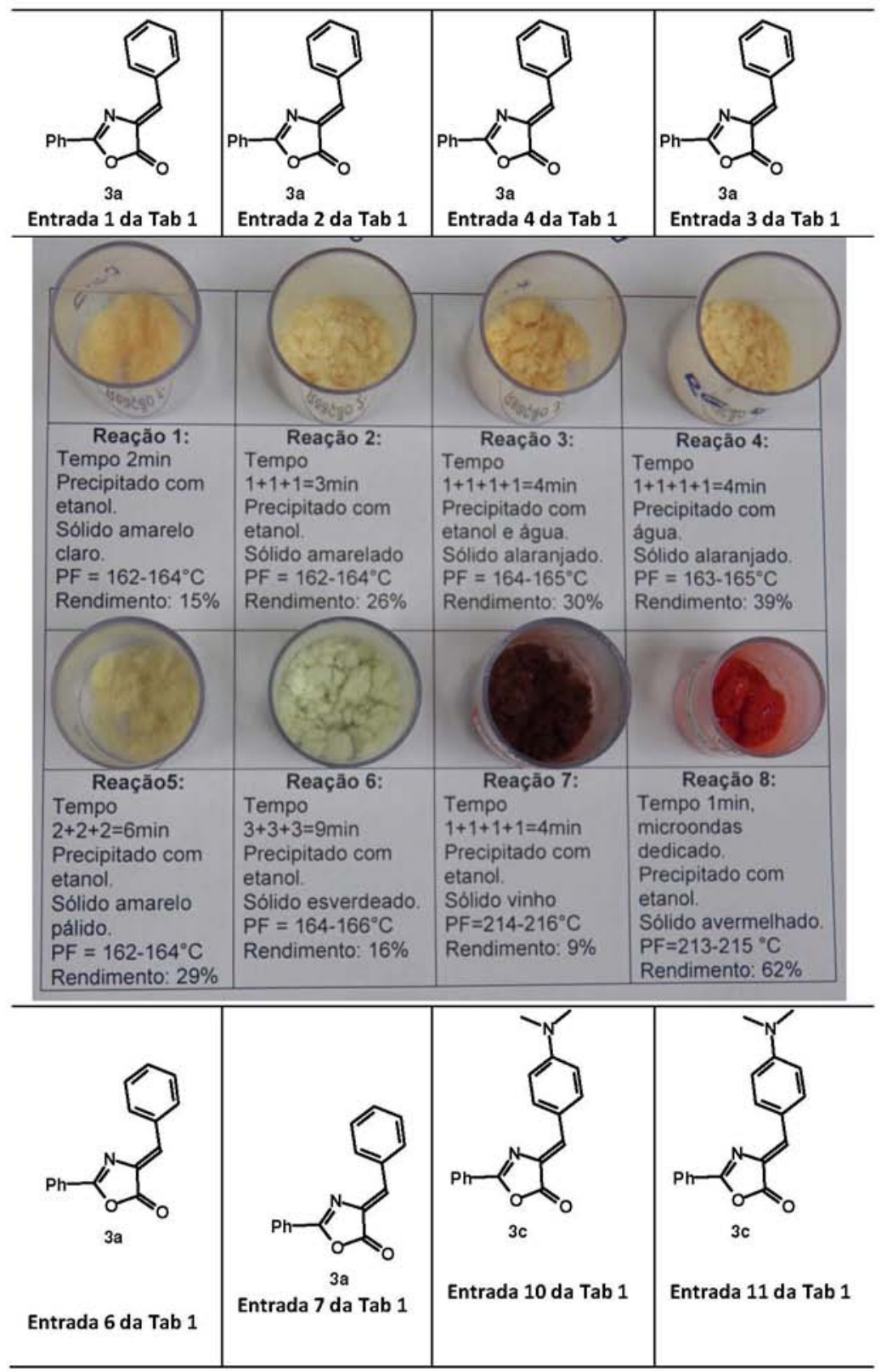

Figura 1S. Fotografia das azalactonas de Erlenmeyer-Plöchl sólidas sintetizadas por radiação micro-ondas em aparelhos doméstico e dedicado 

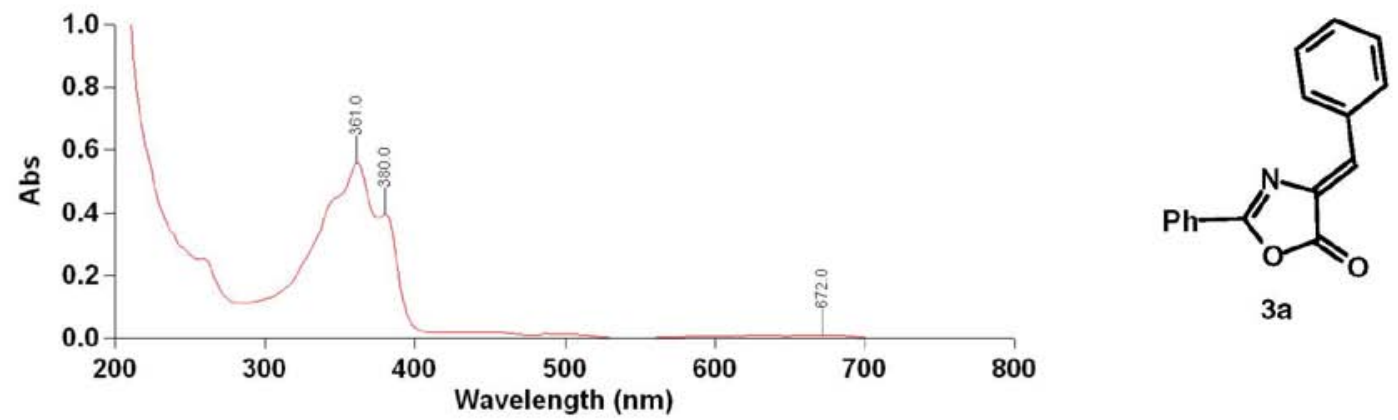

Diclorometano concentração $5 \times 10^{-7} \mathrm{~mol} / \mathrm{L}^{-1}$

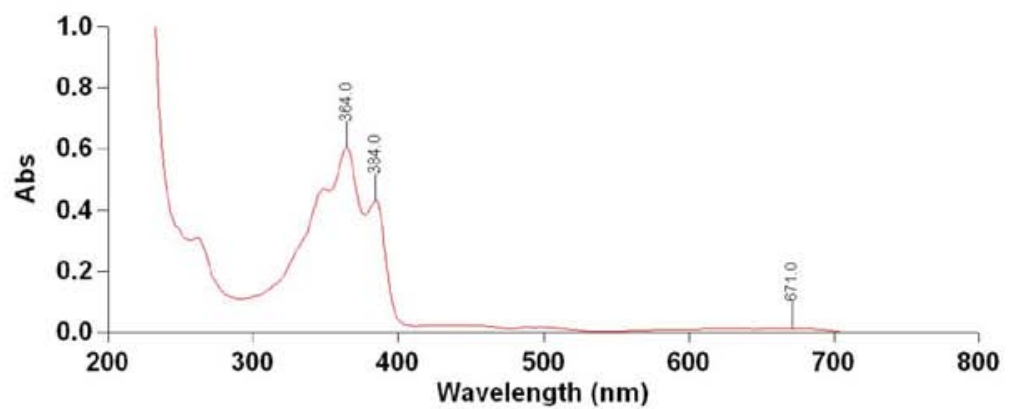

DMSO concentração $5 \times 10^{-7} \mathrm{~mol} / \mathrm{L}^{-1} \mathrm{r}$

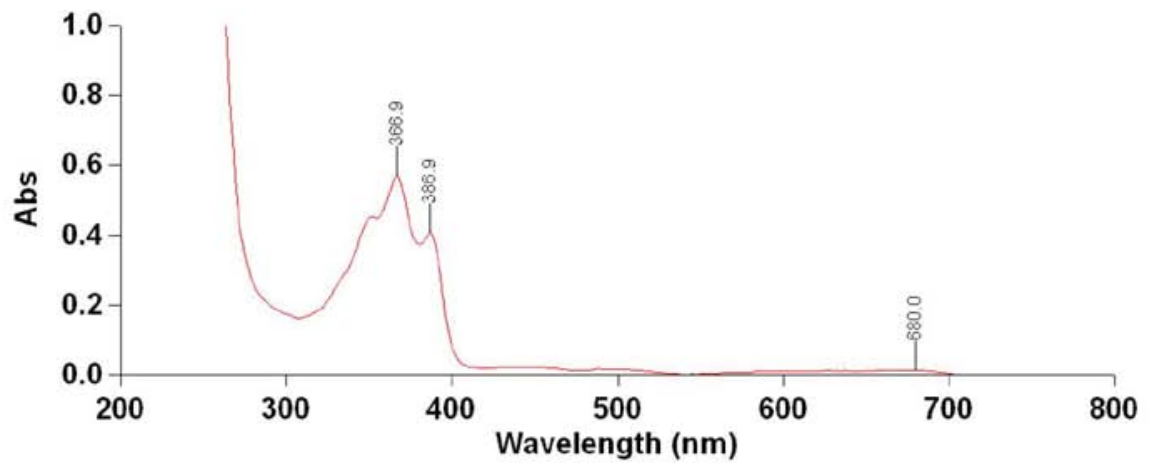

Figura 2S. Espectros de absorção molecular para a fenil benzilideno oxazol-5(4H)-ona 3 a. Etanol concentração $5 \times 10^{-7}$ mol/L ${ }^{-1}$
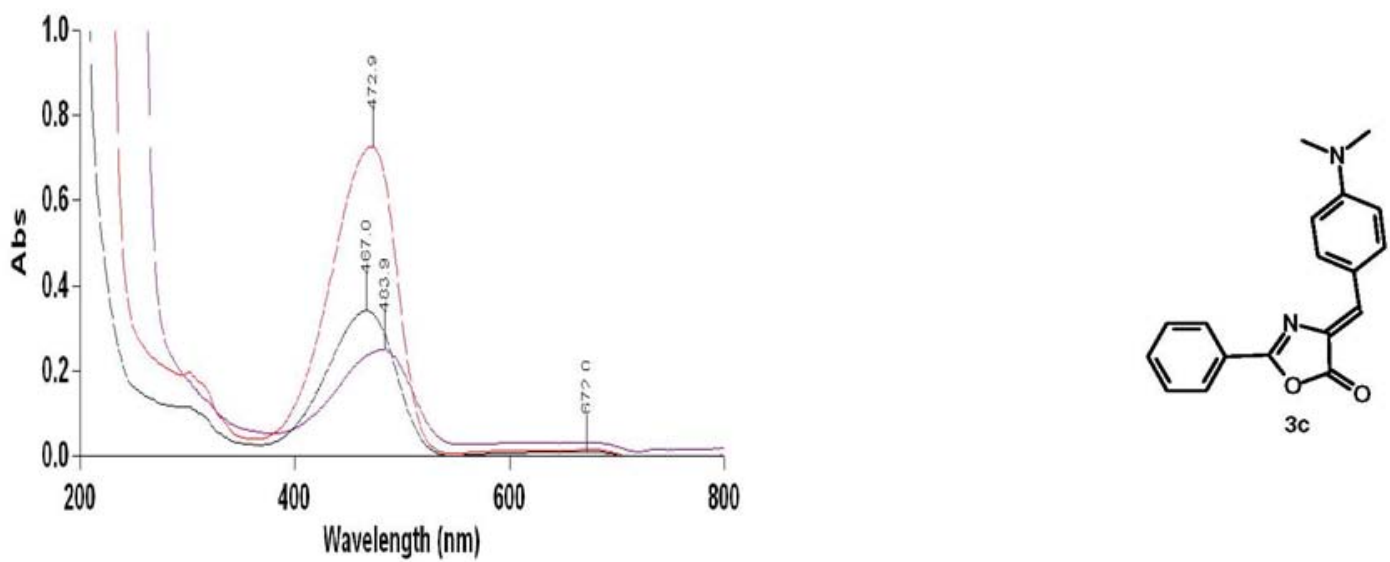

Figura 3S. Espectros de absorção molecular para $3 \mathrm{c} \mathrm{em} \mathrm{CH}_{2} \mathrm{Cl}_{2}\left(5 \times 10^{-7} \mathrm{~mol}^{-1}\right.$, linha vermelha, absorbância máxima 0,738$)$, EtOH (3 x $10^{-7}$ mol/L $\mathrm{L}^{-1}$, linha azul, absorbância máxima 0,342) e em DMSO $\left(5 \times 10^{-7} \mathrm{~mol} / \mathrm{L}^{-1}\right.$, linha roxa, absorbância máxima 0,251 


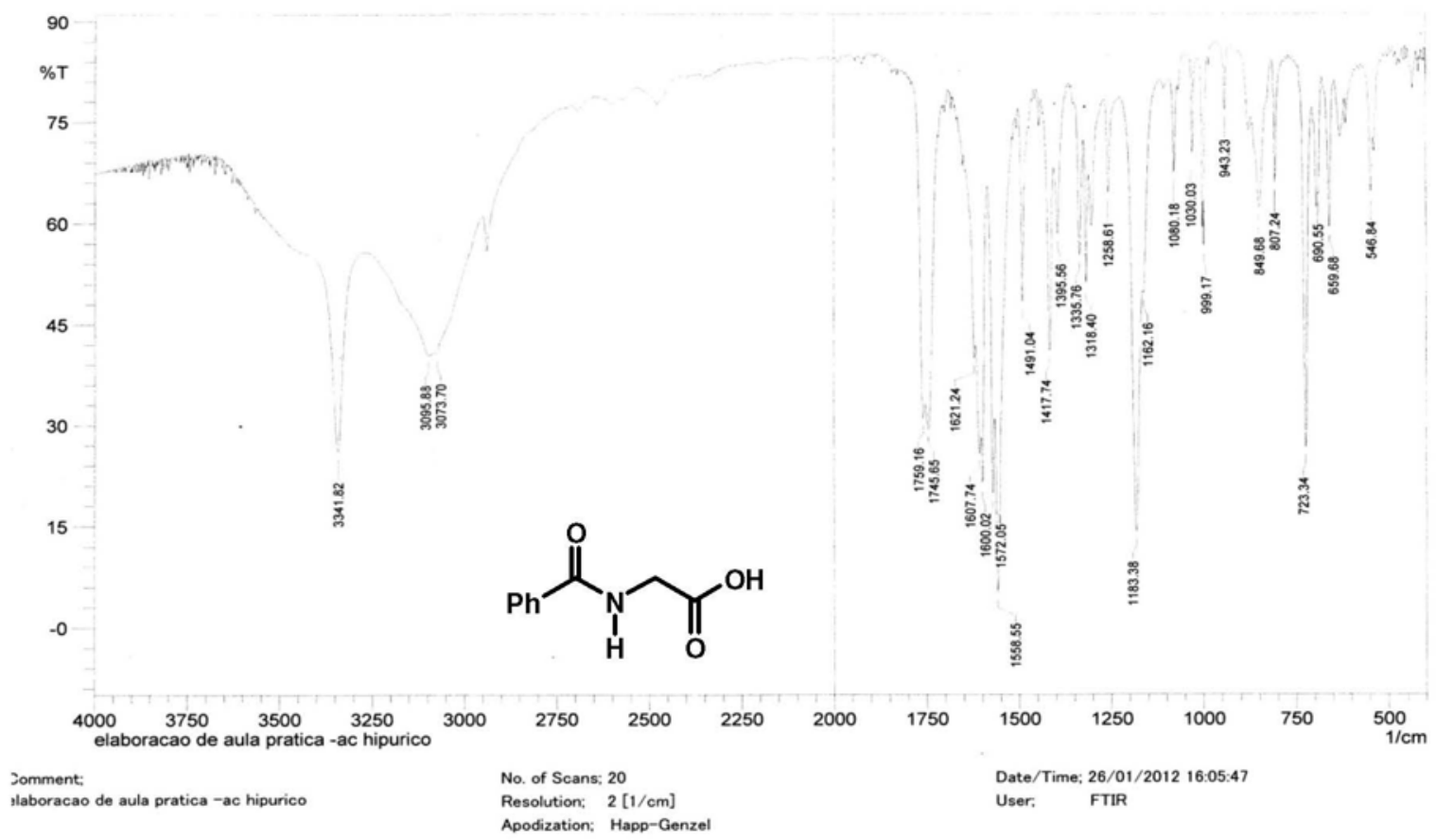

Figura 4S. Espectro na região do infravermelho do ácido hipúrico

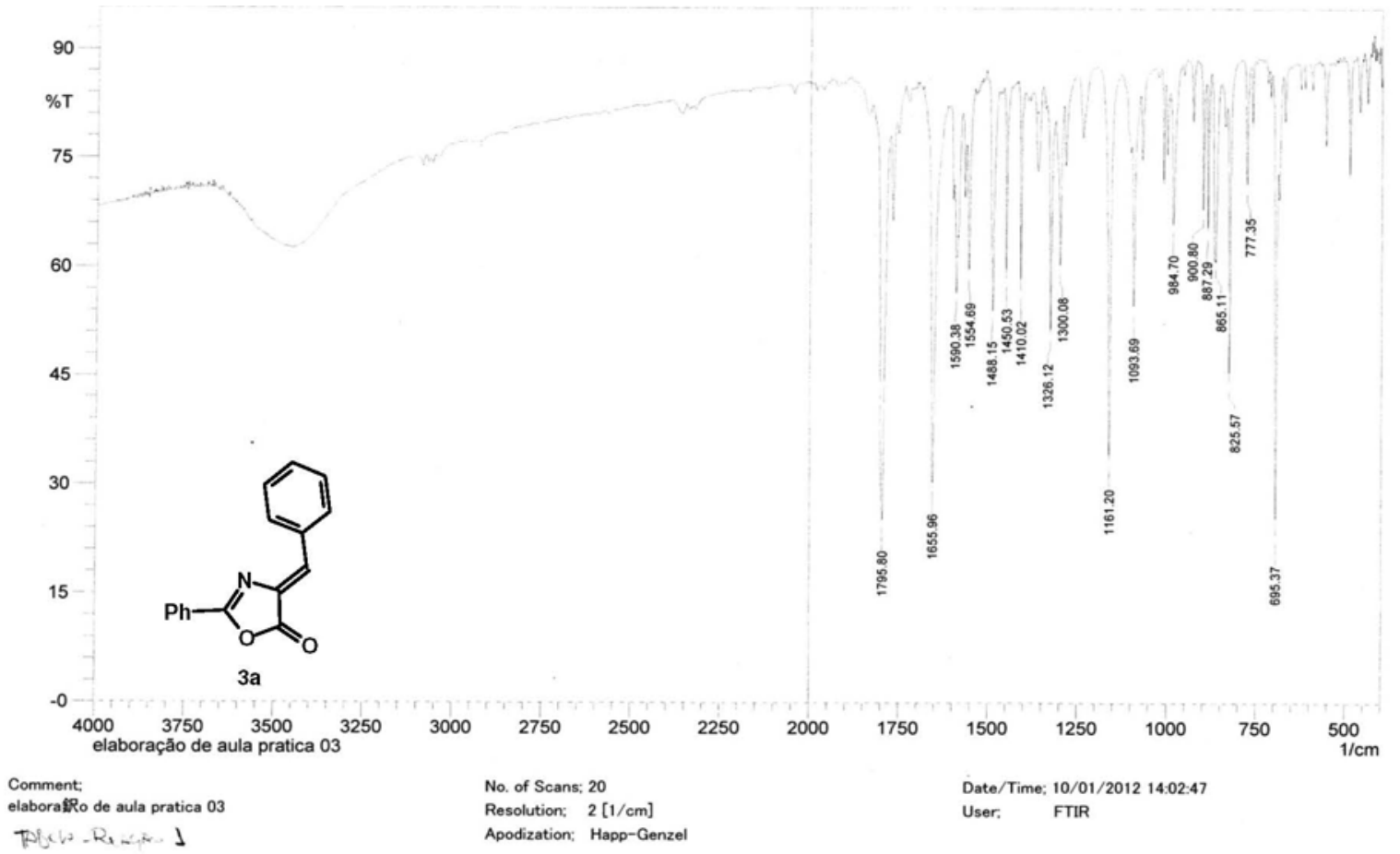

Figura 5S. Espectro na região do infravermelho da azalactona 3 a 


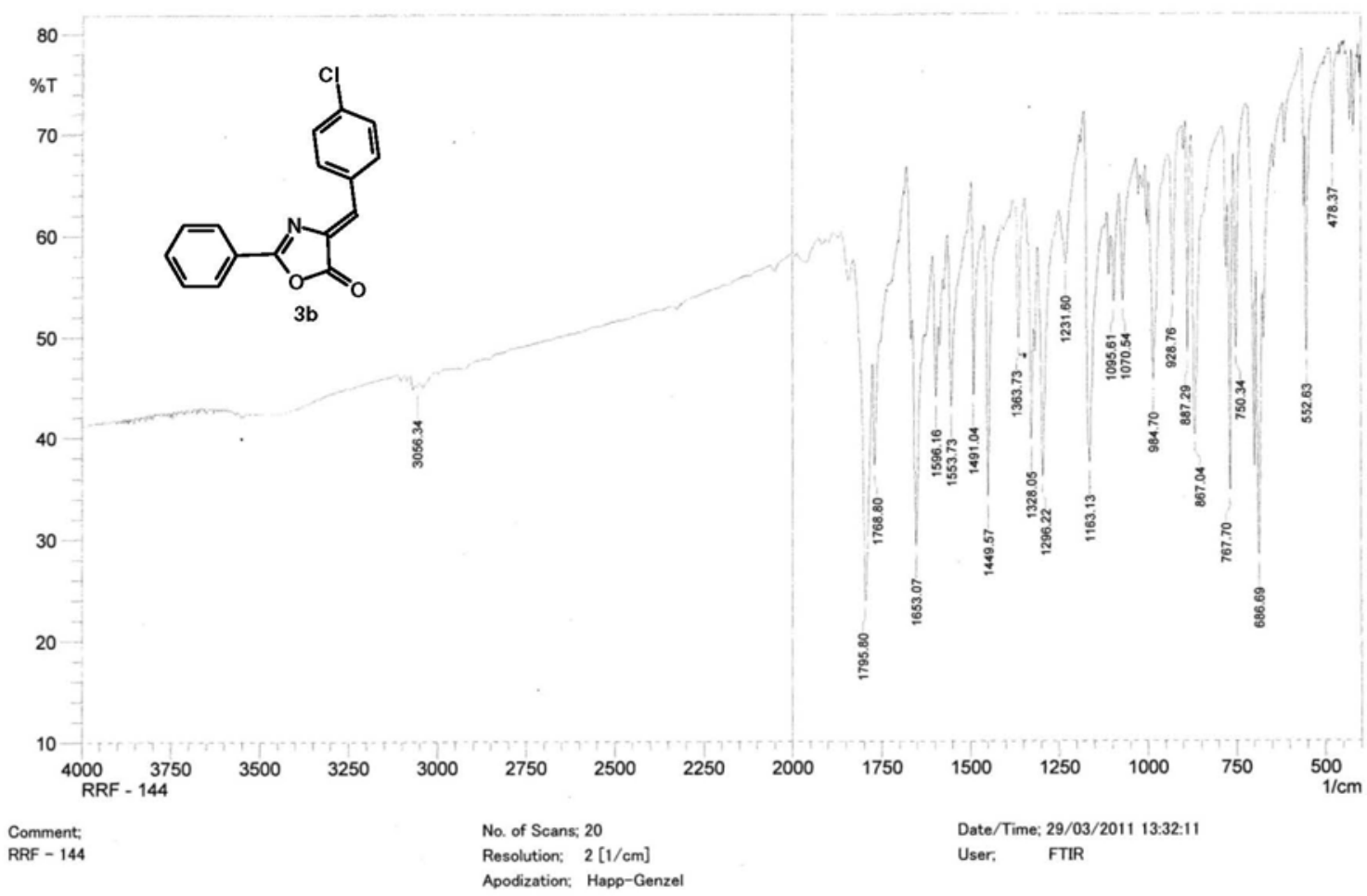

Figura 6S. Espectro na região do infravermelho da azalactona $3 b$

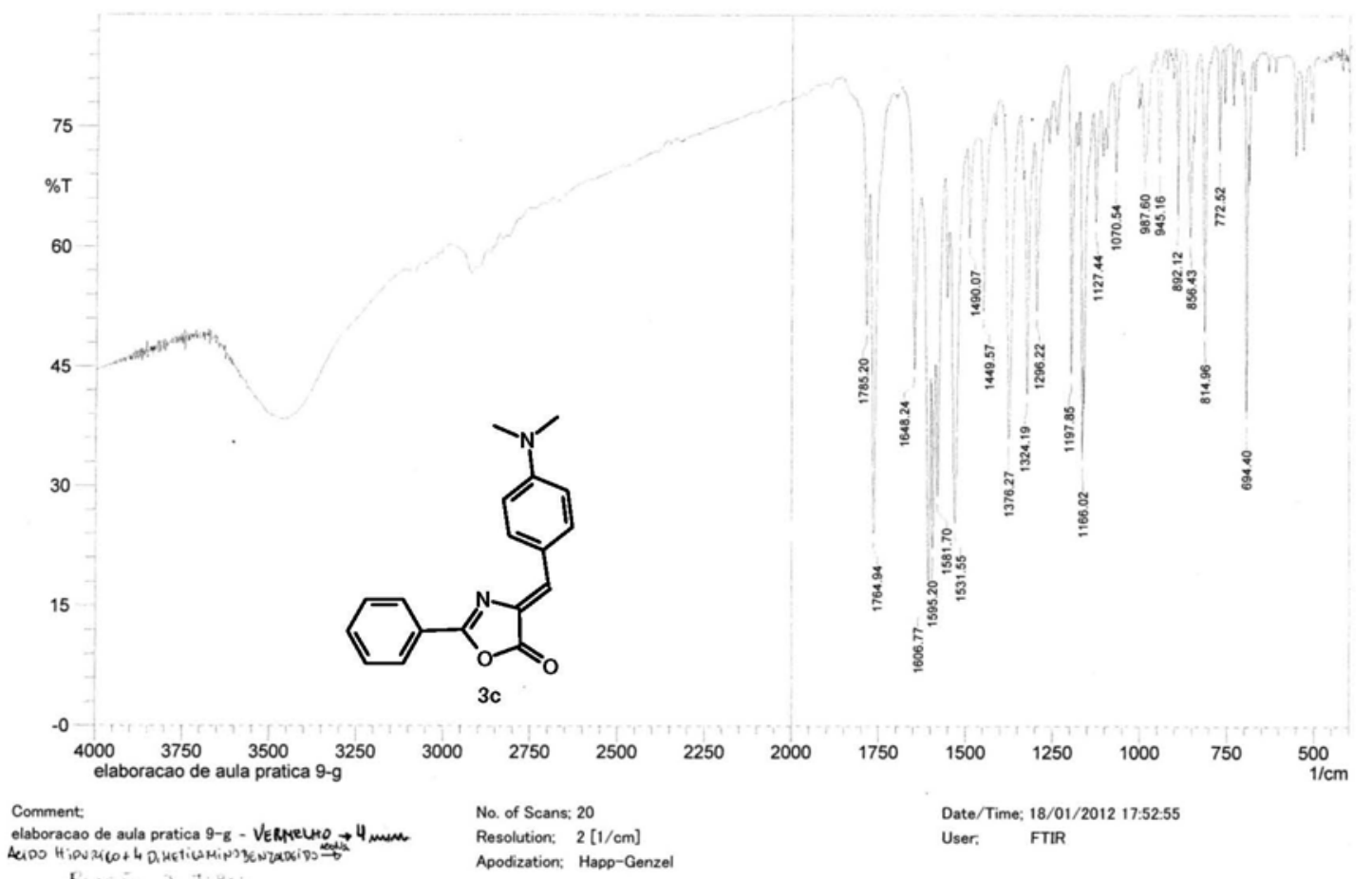

Figura 7S. Espectro na região do infravermelho da azalactona $3 c$ 


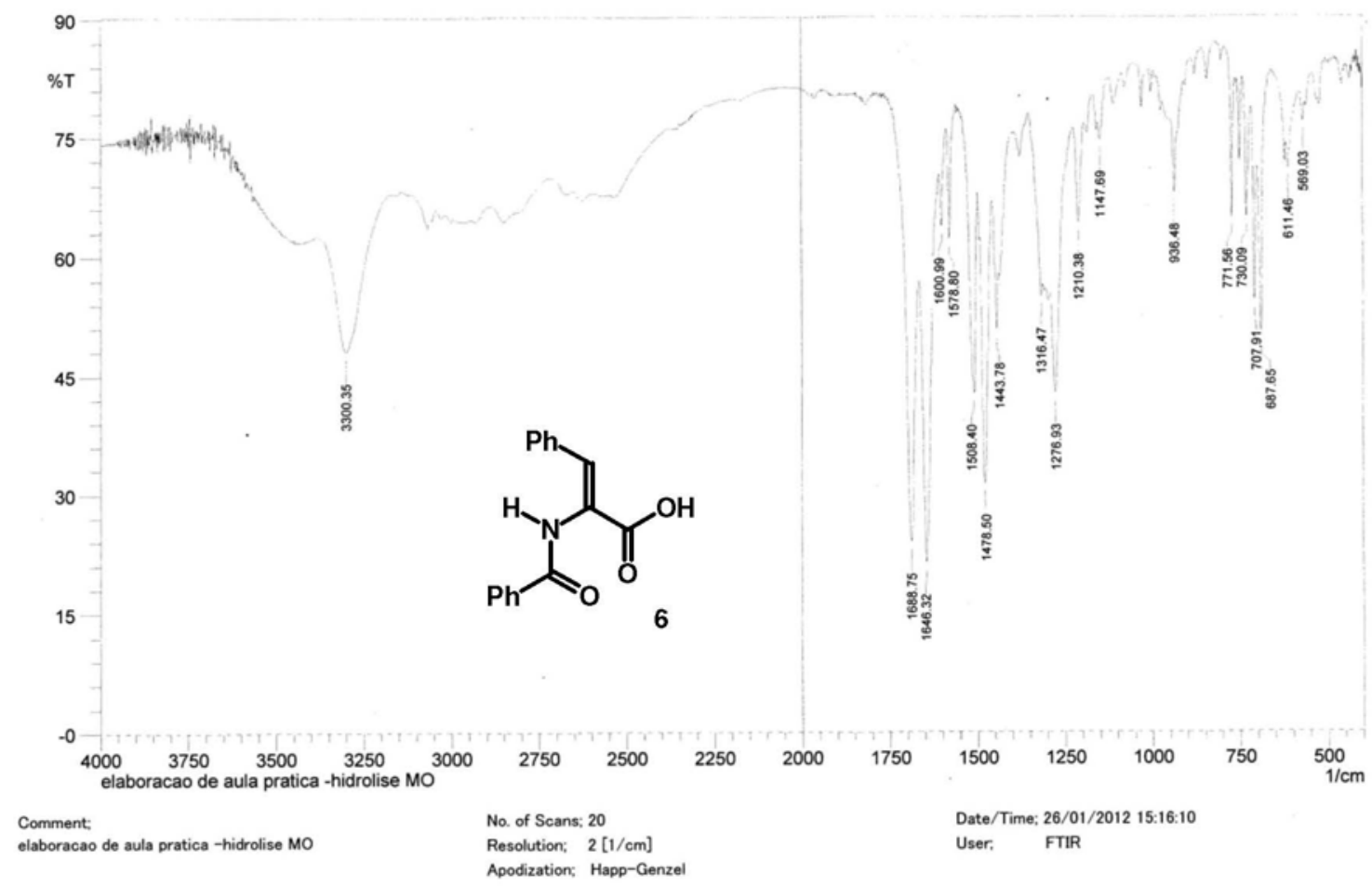

Figura 8S. Espectro na região do infravermelho de 4 
hidrolise 1 H OMSO 25/01/2012

Pulse Sequence: s2pul

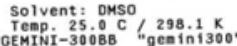

Relax. delay 1.588 sec

Pulse. 44.6 degr ees

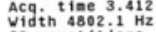

32 repet itions
OBSERVE H1 $300.1326433 \mathrm{MHz}$

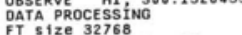

FT size 32768 in, 58 sec
Total time $2=10$.
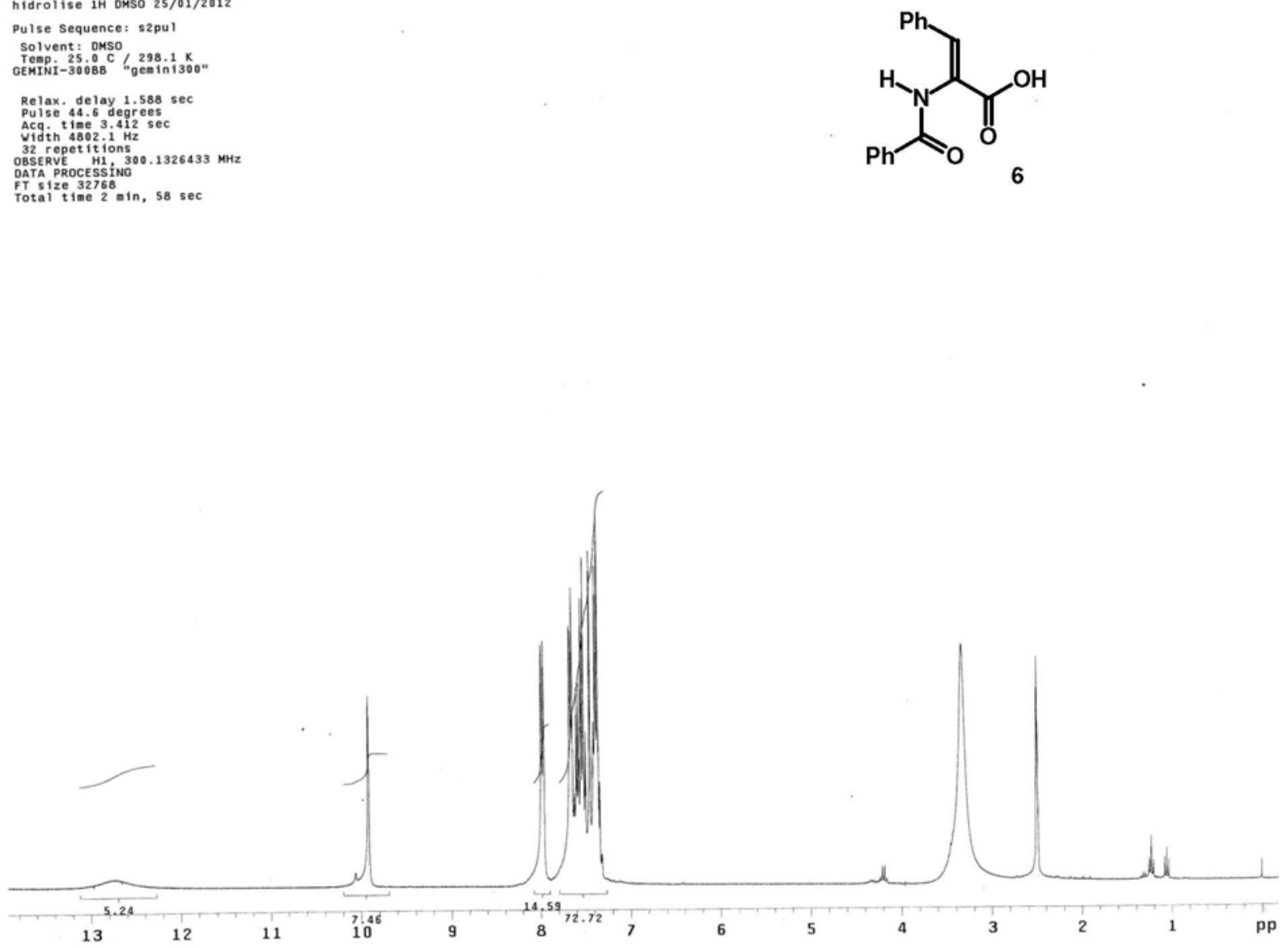

hidrolise 1H OHSO 25/01/2012

Pulse Sequence: s2pul

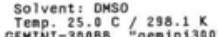

Relax. delay $1.588 \mathrm{sec}$

Pulse 44,6 degrees

vidith ${ }^{4} 4802.1 \mathrm{~Hz}$

35 repettions

OATA PROCESSING
OAT

Total tioe 2 ain, 58 sec

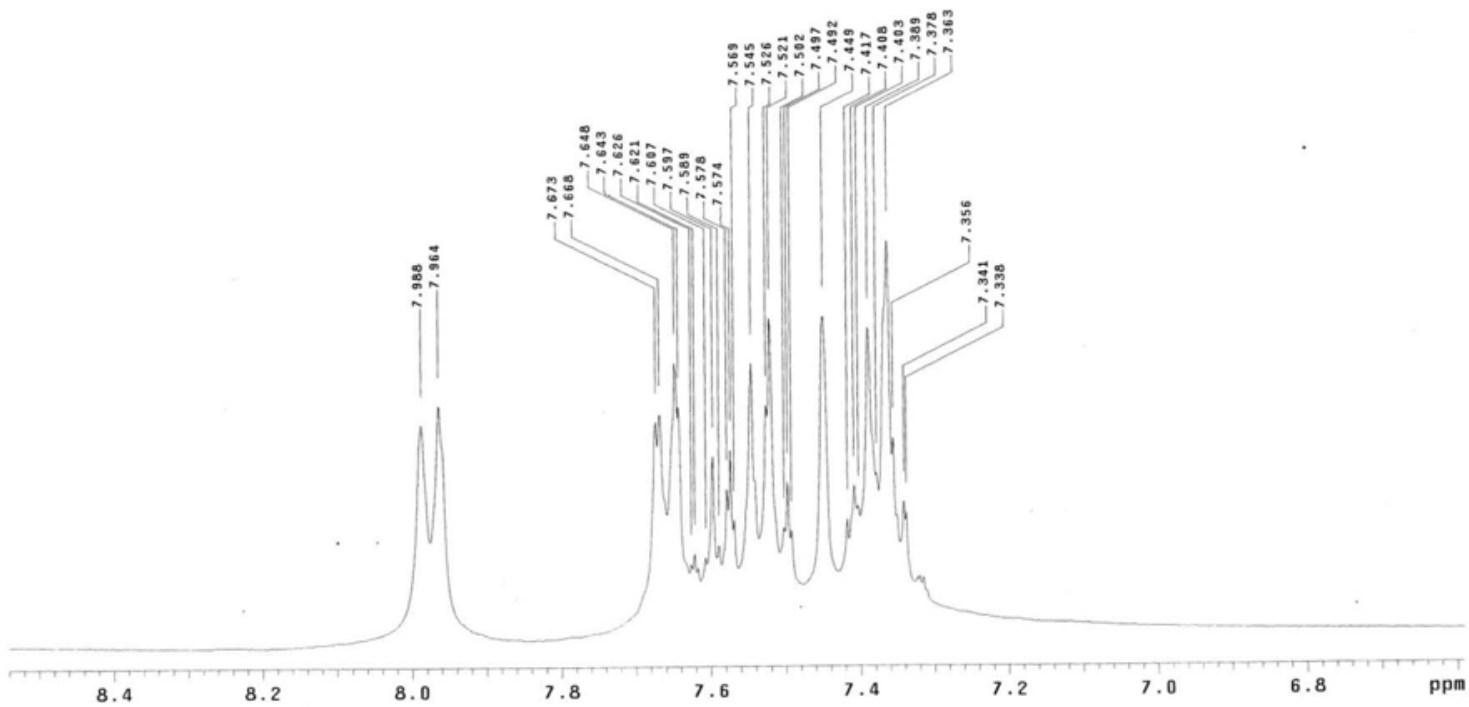

Figura 9S. Espectro de RMN de ${ }^{l} H$ (DMSO-D6) de 6 
Hidrolise $13 \mathrm{C}$ onso $25 / 01 / 2012$ auta pratica

Pulse sequencer szpul

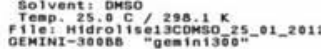

Relax. delay 1.09s sec

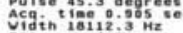

OBSERV CLI3: 75:4584524 MHZ

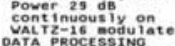

OATA PPocESSING

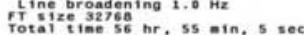<smiles>O=C(O)/C(=C/c1ccccc1)NC(=O)c1ccccc1</smiles>

:

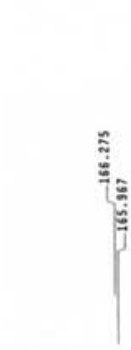
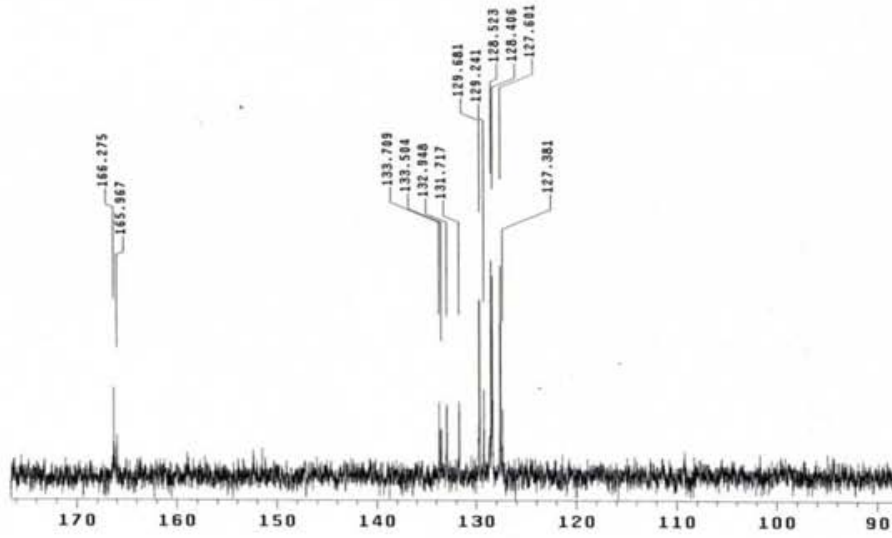

80

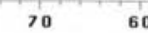

so

40

$30 \quad \mathrm{ppm}$

Hidrolise 13C DMsO 25/01/2012 aula pratica

Pulse Sequence: 52 pul

Solvent: DMsO

Tiemp. $25.00 \mathrm{C}$ ' $298.1 \mathrm{~K}$.

Relax. delay $1.095 \mathrm{sec}$

Pulse. 45.3 degrees

Acg ${ }^{2}{ }^{2}$ ine 0.905 sec

560 repetitions
OBSEVE C13: $75.4584524 \mathrm{MHz}$
DECOUPLE H1: $300.1341489 \mathrm{MHZ}$

power 29 ds
cont inuous $1 y$ on

DATA PROCESSING

FT's Size $32758 \mathrm{~B}$. $1.0 \mathrm{~Hz}$
Total time $56 \mathrm{hr}, 55=1 \mathrm{n}, 5 \mathrm{sec}$

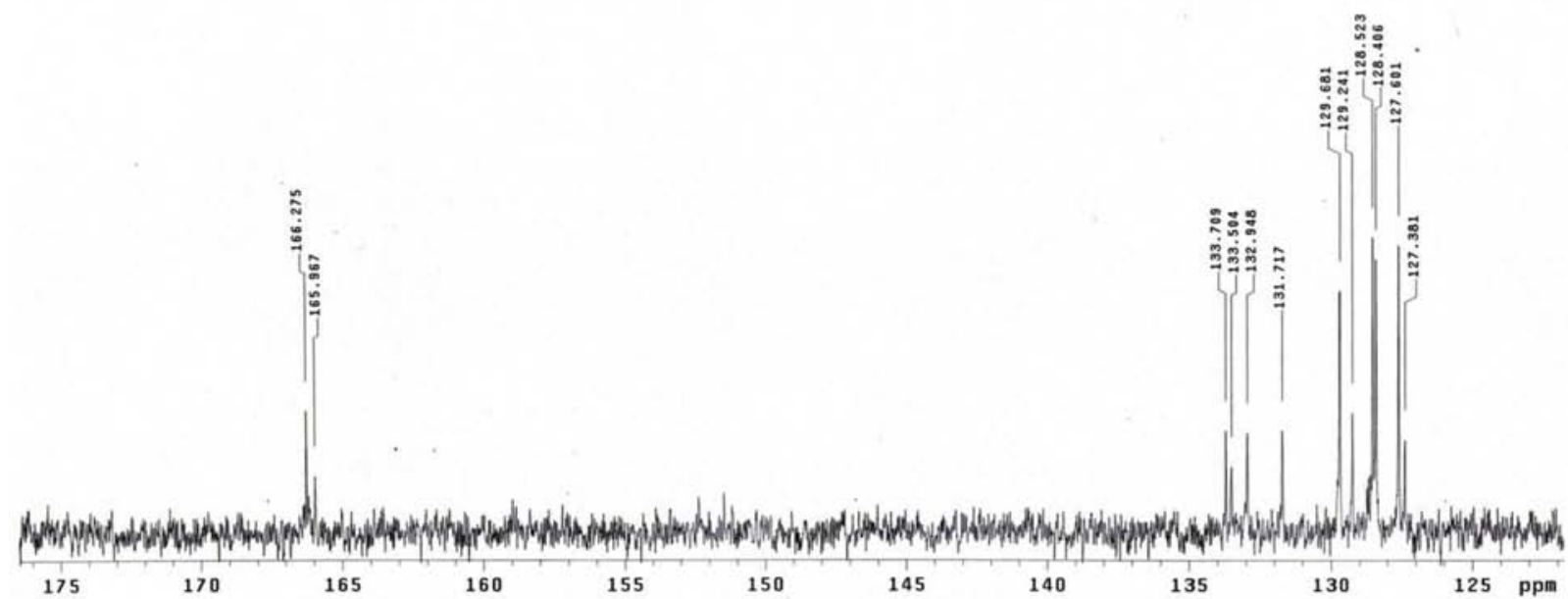

Figura 10S. Espectro de RMN de ${ }^{13} \mathrm{C}(\mathrm{DMSO}-\mathrm{D} 6)$ de 6 